\title{
An Empirical Study on the Impact of Targeted Poverty Alleviation Policies on the Quality of Accounting Information of Manufacturing Companies
}

\author{
Shu $\mathbf{L i}^{*}$, Qing Jin, Ying Liu \\ Accounting School, Shandong Youth University of Political Science, Jinan, Shandong, China \\ *Corresponding Author.
}

\begin{abstract}
Manufacturing is the mainstay of the national economy, the healthy development of manufacturing enterprises is of great significance. Based on the perspective of the quality of accounting information of manufacturing enterprises, the impact of government poverty alleviation policies on manufacturing is analyzed. Using the sample of manufacturing companies from 2016 to 2018, this article empirically examines the impact of manufacturing companies' participation in targeted poverty alleviation led by the government on the quality of their own accounting information. The study found that compared with manufacturing companies that didn't participate, manufacturing companies participating in targeted poverty alleviation showed higher quality of accounting information, and there was a significant positive correlation between the two. And after using the instrumental variable (IV) method to control the endogenous problem, the above conclusions were still stable. Further research found that the above relationship only existed significantly in the sample of non-state-owned manufacturing enterprises. The research has enriched the relevant literature on manufacturing and accounting governance, and has provided some enlightenment for how to improve the quality of accounting information of manufacturing companies against the realistic background.
\end{abstract}

Keywords: Manufacturing companies, targeted poverty alleviation policies, accounting information quality

\section{Introduction}

In order to reduce extreme poverty and consolidate the foundation of governance, the Chinese government has implemented a poverty alleviation policy with "precise identification and precise assistance" as the main method since 2013. Chinese leader requested that "mobilize all social forces to participate in poverty alleviation and encourage and support various enterprises, social organizations, and individuals to participate in poverty alleviation". Targeted poverty alleviation is an important part for companies to fulfill their social responsibilities. ${ }^{[1]}$ In 2016, the China Securities Regulatory Commission (CSRC) issued the "Opinions on Giving Full Play to the Role of Capital Market to Serve the National Poverty Alleviation Strategy", encouraging companies to participate in targeted poverty alleviation. In the same year, the Shanghai Stock Exchange and Shenzhen Stock Exchange also issued detailed requirements for the disclosure of information related to the fulfil of public companies in targeted poverty alleviation. In this context, manufacturing companies have invested a lot of money in targeted poverty alleviation and have also achieved remarkable results. Then, if the perspective is changed, what kind of impact will a manufacturing company have on itself when it fulfills its social responsibility of targeted poverty alleviation? Liu Lili (2019) found that there is a significant positive correlation between the investment ratio of targeted poverty alleviation and enterprise finance performance. ${ }^{[2]}$ The investment in industrial poverty alleviation and the finance performance of enterprises have a stable and positive correlation. Zhang Zenglian and Dong Zhiyuan (2020) used the difference-in-differences model to find that fulfilling targeted poverty alleviation has a significant positive spillover effect on enterprise finance performance. ${ }^{[3]}$ Existing literature mainly discusses the influence on manufacturing companies' participation in targeted poverty alleviation on their financial performance. In addition to this, will this behavior also have an impact on accounting information? Participating in targeted poverty alleviation is a manifestation of corporate social responsibility. Some officials and scholars believe that if a company has a strong sense of social responsibility, it will strictly abide by accounting standards and provide high-quality accounting information. ${ }^{[4]}$ However, the above conclusion lacks the support of empirical evidence. Based on this, this article uses the data of Chinese manufacturing companies from 2016 to 2018 and uses the discretionary accrual level as a

ISSN: 0010-8189 
substitute variable for the quality of accounting information to empirically test the relationship between Chinese manufacturing companies' participation in targeted poverty alleviation and the quality of accounting information. The study found that compared with manufacturing companies that didn't participate, manufacturing companies participating in targeted poverty alleviation showed higher quality of accounting information, and there was a significant positive correlation between the two. And further research found that the above relationship was only significant in the sample of non-state-owned enterprises.

The incremental contribution of this article is that, on the one hand, it confirms the existence of accounting governance effect of manufacturing companies participating in targeted poverty alleviation, expands and deepens the research on the economic consequences of manufacturing companies participating in targeted poverty alleviation, and enriches the theoretical system of manufacturing development. On the other hand, it enriches the literature on the factors affecting the quality of accounting information, and can also provide some useful enlightenment for how to improve the quality of accounting information at present.

\section{Theoretical Analysis and Research Hypothesis}

\subsection{Analysis from the Perspective of Strategic Resources}

Branco and Rodrigues (2006) put forward a hypothesis about the motivation of enterprises to fulfill social responsibility based on the perspective of resources. ${ }^{[5]}$ They believe that enterprises undertaking social responsibility may, on the one hand, generate internal revenue by means of helping enterprises develop or acquire new resources and abilities correlated with proprietary technology and company philosophy; on the other hand, it may obtain external benefits by gaining social reputation. Therefore, enterprise social responsibility is regarded as having strategic value. Specific to targeted poverty alleviation, by participating in targeted poverty alleviation work, on the one hand, companies can obtain benefits by integrating internal and external resources, especially industrial poverty alleviation. Relevant empirical studies have found that since targeted industrial poverty alleviation can enable companies to obtain land, capital and labor, participating in industrial poverty alleviation can achieve economies of scale and improve enterprise performance. The increase and combination of the above production factors will increase the complexity of the company's business, which puts forward higher requirements for the company's internal accounting governance. The accounting system should provide more accurate and timely information and reduce the risks of the accounting system due to the complexity of the business. This may cause the management to increase investment and attention to the accounting system, such as selecting or upgrading a more reliable and effective accounting information system, and hiring higher-quality accounting personnel. The above measures will ultimately be reflected in the improvement of the quality of accounting information. On the other hand, companies actively fulfilling their social responsibilities will form a benign corporate culture within the company. Studies have confirmed or believed that a corporate culture of integrity can lower the level of earnings management of enterprises, and a corporate culture that ignores social responsibility will significantly affect earnings management. ${ }^{[6]}$ The underlying mechanism may be that the corporate culture that emphasizes responsibility to others and society will affect the producers and decision makers of accounting information in the enterprise, making them more concerned about the accounting information needs of the various stakeholders of the enterprise, and producing more authentic and fair accounting information, which inversely will improve the quality of accounting information.

Participating in targeted poverty alleviation has also enabled the company to gain social reputation, and this kind of social reputation will receive positive feedback from the capital market. manufacturing companies participating in targeted poverty alleviation achieved higher cumulative abnormal return. Social reputation is an important strategic capital of a company, and the company's earnings manipulation behavior will depreciate or even lose this strategic capital. The empirical research found that a good social reputation significantly inhibits the positive and true earnings management level of companies. At the same time, one of the motivations for companies to participate in targeted poverty alleviation may be to get more media attention. Research by Huang Jun, Li Yun, and Duan Zhixin (2020) found that media attention has positive significance correlated with the willingness of manufacturing companies to

ISSN: 0010-8189 
participate in targeted poverty alleviation, and when media attention is high, companies invest more in targeted poverty alleviation. ${ }^{[7]}$ Companies participating in targeted poverty alleviation will gain greater media attention. At this time, if companies are found to provide low-quality or even false accounting information, just like "ill news flies apace", under the eyeball effect, they will bear huge costs. Studies have confirmed that media attention can play a role in corporate governance, and supervision from the media can significantly reduce the frequency of violations by manufacturing companies. ${ }^{[8]}$ In summary, from the perspective of social reputation and media attention, companies participating in targeted poverty alleviation are more motivated to provide higher-quality accounting information.

\subsection{Analysis from the Perspective of Political Connection}

Combined with China's institutional background, in addition to the aforementioned factors such as the integration of internal resources, company philosophy, and social reputation of Branco and Rodrigues (2006), political factors may also be an important motivation for companies to participate in targeted poverty alleviation. Under China's current institutional environment, government behavior has an important impact on the allocation of resources. The change of term of office of local government will significantly increase charitable donations by local enterprises, and believed that the charitable donations of Chinese private enterprises were in a sense to establish a political relationship. The goal of "all the rural poor population under the current standards will be lifted out of poverty by 2020 " brings current political pressure on local governments. They have the motivation and ability to transmit this pressure to enterprises, and enterprises also have the incentive to bear the political costs related to this in order to obtain corresponding resource support from the government now or in the future, such as obtaining the corresponding policy and financial support or the relaxation of supervision from the government. An empirical study by Nie Jun, Ran Rong, and Tang Yuanlong (2020) found that the greater the fiscal pressure in a region, the more companies in the region invest in targeted poverty alleviation. It can be seen that enterprises can establish a certain degree of political connection with local governments by participating in targeted poverty alleviation. ${ }^{\left[{ }^{9]}\right.}$ Political connection provides room for earnings manipulation, and aggravates the risk of corporate financial information quality. ${ }^{[10]}$ Private companies with political connection have a larger scale of earnings management. Wu Liansheng (2010) found that, compared with non-politically associated enterprises, politically associated enterprises reduce their tax burden through downward earnings management. ${ }^{[11]}$ Therefore, from the viewpoint of political factors, participation in targeted poverty alleviation is related to lower quality of accounting information.

In summary, from the perspective of strategic resources, from the analysis of motivations such as internal resource integration, corporate culture and social reputation, and media attention, it can be inferred that companies fulfilling targeted poverty alleviation are more motivated to provide higher-quality accounting information. However, from the viewpoint of political connection, participation in targeted poverty alleviation is related to lower quality of accounting information. Therefore, the following two competing hypotheses are proposed:

Hypothesis 1a: manufacturing companies participating in targeted poverty alleviation are positively related to the quality of their accounting information, that is, manufacturing companies participating in targeted poverty alleviation show higher quality of accounting information.

Hypothesis $1 \mathrm{~b}$ : manufacturing companies participating in targeted poverty alleviation are negatively related to the quality of their accounting information, that is, manufacturing companies participating in targeted poverty alleviation show lower quality of accounting information.

\section{Research Design}

\subsection{Data Selection}

Shanghai Stock Exchange and Shenzhen Stock Exchange have included information related to poverty alleviation work in the scope of information disclosure of manufacturing companies since 2016. Therefore, this article selects the data of A-share manufacturing companies from 2016 to 2018 for follow-up empirical analysis. The relevant data

ISSN: 0010-8189 
comes from the CSMAR, statistical yearbook and some manual collation. In order to exclude the influence of particular values, ST and PT manufacturing companies are eliminated from the sample of manufacturing companies. Finally, a total of 8,931 samples are collected over 3 years; in addition, Winsorize is applied to all continuous variables by about $5 \%$ to prevent the influence of extreme values.

\subsection{Variable Setting}

In this article, the explanatory variable is set as a dummy variable (fp) whether to participate in targeted poverty alleviation or not. If a manufacturing company disclosed its fulfilling targeted poverty alleviation in its annual report that year, the variable is assigned a value of 1 ; otherwise, it is assigned a value of 0 .

This article selects the discretionary accrual level as a substitute variable (|DA|) for the quality of accounting information. Huang Mei and Xia Xinping (2009) comprehensively compared several existing models for calculating the discretionary accrual level and found that the Dechow (1995) revised model by industry and by year performed best in this setting of China's reality. ${ }^{[12]}$ Therefore, this article chooses this indicator as the explained variable, and the specific calculation method of this variable is:

$$
\begin{aligned}
& \mathrm{TA}_{\mathrm{i}, \mathrm{I}} / \text { Asset }_{\mathrm{i}, \mathrm{t}-1}=\alpha 1 * 1 / \text { Asset }_{\mathrm{i}, \mathrm{-}-1}+\alpha 2 * \triangle \mathrm{REV}_{\mathrm{i}, \mathrm{l}} / \text { Asset }_{\mathrm{i}, \mathrm{t}-1}+\alpha 3 * \mathrm{PPE}_{\mathrm{i}, \mathrm{l}} / \text { Asset }_{\mathrm{i}, \mathrm{t}-1}+\varepsilon_{\mathrm{i}, \mathrm{t}} \\
& \mathrm{DA}_{\mathrm{i}, \mathrm{t}}=\mathrm{TA}_{\mathrm{i}, \mathrm{l}} / \mathrm{Asset}_{\mathrm{i}, \mathrm{t}-1}-\alpha 1^{*} 1 / \mathrm{Asset}_{\mathrm{i}, \mathrm{t}-1}-\alpha 2^{*}\left(\triangle \mathrm{REV}_{\mathrm{i}, \mathrm{t}} \triangle \mathrm{REC}_{\mathrm{i}, \mathrm{t}}\right) / \text { Asset }_{\mathrm{i}, \mathrm{t}-1}-\alpha 3^{*} \mathrm{PPE}_{\mathrm{i}, \mathrm{t}} / \mathrm{Asset}_{\mathrm{i}, \mathrm{t}-1}
\end{aligned}
$$

Among them, $\mathrm{DA}_{\mathrm{i}, \mathrm{t}}$ represents discretionary accruals, $\mathrm{TA}_{\mathrm{i}, \mathrm{t}}$ represents total accruals in $\mathrm{t}$ year, Asset $_{\mathrm{i}, \mathrm{t}-1}$ represents total assets at the end of $\mathrm{t}-1$ year, and $\triangle \mathrm{REV}_{\mathrm{i}, \mathrm{t}}$ represents main operating revenue in $\mathrm{t}$ year minus $\mathrm{t}-1$ year's main operating revenue, $\mathrm{PPE}_{\mathrm{i}, \mathrm{t}}$ represents the original value of fixed assets at the end of $t$ year, $\triangle \mathrm{REC} \mathrm{C}_{\mathrm{i}, \mathrm{t}}$ represents the accounts receivable in $t$ year minus the accounts receivable at the end of $t-1$ year. ${ }^{[13]}$

After bringing the estimated coefficients obtained in the above model (1) to the model (2), and then taking the absolute value of the obtained data, the discretionary accrual level can be obtained. The larger the value is, the lower the quality of accounting information will be. On the contrary, the smaller the value is, the higher the quality of accounting information will be.

Drawing lessons from existing research, this article selects variables including return on equity, two-post in one of chairman and general manager, financial leverage, shareholding ratio of the largest shareholder, company size, nature of property rights, company growth, and whether in badly polluted industry, and controls the fixed effect of industry and year. The detailed setting of every variable is shown in "Table 1" below:

\begin{tabular}{|c|c|c|}
\hline $\begin{array}{l}\text { Explained } \\
\text { variable }\end{array}$ & $|\mathrm{DA}|$ & $\begin{array}{l}\text { The absolute value of the discretionary accrual level, which is } \\
\text { used to indicate the quality of accounting information }\end{array}$ \\
\hline $\begin{array}{l}\text { Explanatory } \\
\text { variable }\end{array}$ & $\mathrm{fp}$ & $\begin{array}{l}\text { Dummy variable. If the company participated in targeted } \\
\text { poverty alleviation that year, } 1 \text { will be taken, otherwise, } 0 \\
\text { will be taken }\end{array}$ \\
\hline \multirow{5}{*}{$\begin{array}{l}\text { Control } \\
\text { variable }\end{array}$} & $\operatorname{lna}$ & $\begin{array}{c}\text { Company size, the natural logarithm of the company's total } \\
\text { assets }\end{array}$ \\
\hline & roe & Return on equity at the end of the period \\
\hline & $\mathrm{mp}$ & $\begin{array}{l}\text { Two-post in one. If the chairman and the general manager are } \\
\text { the same person, take } 1 \text {; otherwise, take } 0\end{array}$ \\
\hline & lev & $\begin{array}{l}\text { Financial leverage: Total asset-liability ratio at the end of the } \\
\text { period }\end{array}$ \\
\hline & Top1 & The company's largest shareholder's shareholding ratio \\
\hline
\end{tabular}

Table 1 Variable Definition Table

ISSN: 0010-8189 


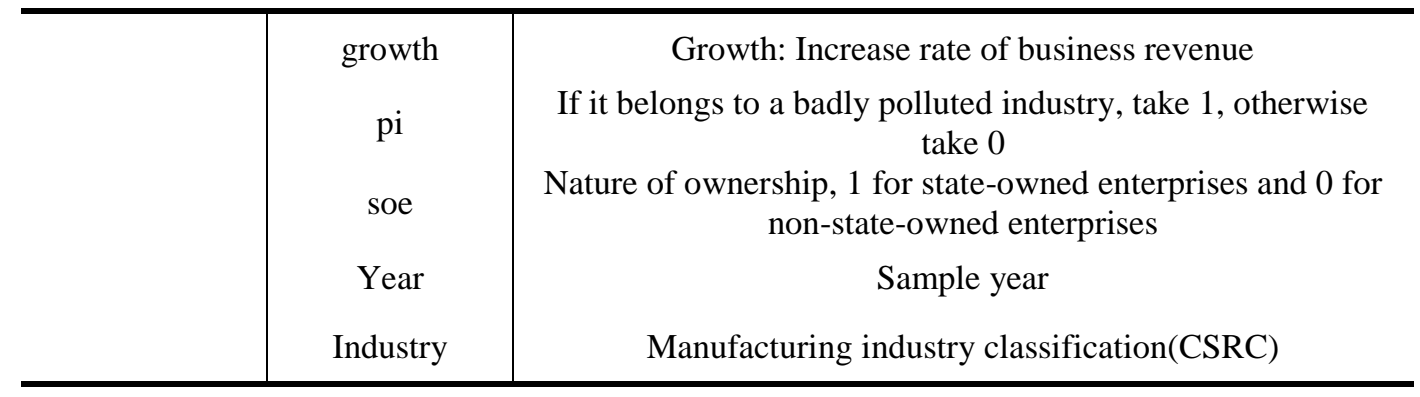

\subsection{Model Selection}

In order to verify the research hypothesis, this article constructs a multiple linear regression model (3), as shown below:

$$
|\mathrm{DA}|=\beta_{0}+\beta_{1} * \mathrm{fp}+\sum \text { Control }+\sum \text { Year }+\sum \text { Industry }+\varepsilon
$$

In the model, if the empirical results indicate that the estimated coefficient $\beta_{1}$ is significantly less than 0 , it supports hypothesis $1 \mathrm{a}$, that is, participation in targeted poverty alleviation is positively related to the quality of accounting information, and manufacturing companies participating in targeted poverty alleviation show higher quality of accounting information. Conversely, if the estimated coefficient $\beta_{1}$ is significantly greater than 0 , hypothesis $1 \mathrm{~b}$ is supported, and participation in targeted poverty alleviation is negatively related to the quality of accounting information.

\section{Empirical Results}

\subsection{Descriptive statistics}

The results of descriptive statistics are shown in "Table 2" below:

Table 2 Descriptive Statistics Table

\begin{tabular}{c|ccccc}
\hline & Maximum & Minimum & Average & Median & $\begin{array}{c}\text { Standard } \\
\text { deviation }\end{array}$ \\
\hline |DA $\mid$ & 0.189 & 0.003 & 0.054 & 0.038 & 0.050 \\
$\mathrm{fp}$ & 1 & 0 & 0.277 & 0 & 0.447 \\
lna & 24.706 & 20.470 & 22.285 & 22.167 & 1.161 \\
roe & 0.194 & -0.140 & 0.642 & 0.658 & 0.075 \\
mp & 1 & 0 & 0.283 & 0 & 0.450 \\
lev & 3.919 & 0.010 & 0.424 & 0.413 & 0.210 \\
Top1 & 0.605 & 0.132 & 0.333 & 0.313 & 13.496 \\
growth & 0.916 & -0.256 & 0.186 & 0.134 & 0.282 \\
pi & 1 & 0 & 0.364 & 0 & 0.481 \\
soe & 1 & 0 & 0.325 & 0 & 0.469 \\
\hline
\end{tabular}

From the results in "Table 2" above, in the sample selected in this article, about $27.7 \%$ of manufacturing companies disclosed their participation in targeted poverty alleviation in their 2016-2018 annual reports. The maximum absolute value $(|\mathrm{DA}|)$ of the discretionary accrual is 0.189 , the minimum is 0.003 , the average is 0.054 , and the

ISSN: 0010-8189 
median is 0.038 . And from the standard deviation, this variable has certain variability.

\subsection{Regression analysis}

The regression analysis results are shown in "Table 3" below:

Table 3 Regression Coefficient Table

\begin{tabular}{|c|c|}
\hline & $|\mathrm{DA}|$ \\
\hline $\mathrm{fp}$ & $\begin{array}{c}-0.004 * * * \\
(-3.32)\end{array}$ \\
\hline $\operatorname{lna}$ & $\begin{array}{c}-0.006 * * * \\
(-9.72)\end{array}$ \\
\hline roe & $\begin{array}{c}-0.05 * * * \\
(-5.33)\end{array}$ \\
\hline $\mathrm{mp}$ & $\begin{array}{c}0.0017 \\
(1.40)\end{array}$ \\
\hline lev & $\begin{array}{c}0.04 * * * \\
(12.68)\end{array}$ \\
\hline Top1 & $\begin{array}{l}-0.0001 \\
(-1.42)\end{array}$ \\
\hline growth & $\begin{array}{c}0.015^{* * *} \\
(6.42)\end{array}$ \\
\hline pi & $\begin{array}{l}-0.001 \\
(-0.94)\end{array}$ \\
\hline soe & $\begin{array}{c}-0.005 * * * \\
(-3.56)\end{array}$ \\
\hline Constant term & $\begin{array}{c}0.16 * * * \\
(12.62)\end{array}$ \\
\hline Industry & Control \\
\hline Year & Control \\
\hline Sample size & 8931 \\
\hline
\end{tabular}

Note: $\mathrm{T}$ values are shown in brackets, and the regression has been adjusted through White heteroscedasticity, the same as below.

The results in "Table 3" show that after controlling other variables, the negative correlation between fp and |DA| is still significant, the regression coefficient is -0.004 and it is significant at the $1 \%$ level. This result supports Hypothesis 1a: manufacturing companies participating in targeted poverty alleviation is positively related to the quality of their accounting information, that is, manufacturing companies participating in targeted poverty alleviation show higher quality of accounting information. This result supports the hypothesis related to strategic resources, that is, the purpose of manufacturing companies' participation in targeted poverty alleviation is to obtain strategic resources support from both internal (resource integration, corporate culture) and external (social reputation, media attention). The empirical results do not support the hypothesis of political connection.

\section{Robustness Test}

5.1 Variable substitution

ISSN: 0010-8189

(C) CONVERTER 2020 
Although the Dechow (1995) revised model by industry and by year is the best choice, in order to make the research conclusions more stable, three different methods, namely, basic Jones model, Jones model based on performance correction and DD model, are used to recalculate the absolute value of discretionary accruals respectively, and the explained variables are replaced. Before and after the replacement, the main conclusion has not changed substantially.

\subsection{Endogenous test}

Further, in order to alleviate the endogenous problems of missing variables and reciprocal causation that may exist in the study, this article uses two instrumental variables at the same time; one is the annual per capital electricity consumption in the rural areas where the manufacturing company is located, and the other is the "equality" social value index of the province where the location of manufacturing company (Schwartz's (2008) social values of equality emphasize social fairness, equality, responsibility, mutual assistance and honesty). It uses the two stage least square method to test the basic conclusions. The test results are shown in "Table 4" below:

Table 4 2SLS Regression Results

\begin{tabular}{c|c}
\hline & $|\mathrm{DA}|$ \\
\hline $\mathrm{Fp}$ & $-0.021^{* * *}$ \\
& $(-2.70)$ \\
Control variable & Control \\
Sample size & 8931 \\
\hline
\end{tabular}

Note: Only the regression results of the second stage are reported, and the $\mathrm{z}$ value is in parentheses. And the instrumental variables pass the weak instrumental variables $(\mathrm{F}=96.39)$ and the over-identification test $(\mathrm{P}=0.33)$.

From the results in "Table 4", after using the instrumental variables, fp and |DA| still show a significant negative correlation (the coefficient is -0.021 , which is significant at the $1 \%$ level), and the research conclusions of this article are still valid.

\section{Further Analysis of The Nature of Property Right}

In the context of China's dual ownership structure, enterprises with different property rights may have different motivations for participating in poverty alleviation, therefore, this article conducts a group regression according to the different property rights of the sample companies, and the results are shown in "Table 5" below:

Table 5 Regression Coefficient Table

\begin{tabular}{c|c|c}
\hline & $\begin{array}{c}\text { State-owned } \\
\text { enterprise }\end{array}$ & Non-state-owned enterprise \\
\hline $\mathrm{fp}$ & -0.003 & $-0.005^{* * * *}$ \\
Control variable & $(-1.49)$ & $(-2.86)$ \\
Industry & Control & Control \\
Year & Control & Control \\
Sample size & 2906 & Control \\
\hline Note: The t value is in brackets & & 6025 \\
\hline
\end{tabular}

ISSN: 0010-8189 
From the results of the above table, in the sample of state-owned enterprises, the regression coefficient of fp is -0.003 , although it is less than 0 , it is not significant. In the sample of non-state-owned enterprises, the regression coefficient of $\mathrm{fp}$ is -0.005 , and it is significant at the $1 \%$ level. The positive correlation between the participation of manufacturing companies in targeted poverty alleviation and the quality of accounting information is only significant in the sample of non-state-owned enterprises. The reason for this difference may be that, unlike non-state-owned enterprises, state-owned enterprises fulfilling targeted poverty alleviation to complete the corresponding political tasks to a greater extent, which is an obligation that they need to undertake. For example, when governments at all levels allocate poverty alleviation tasks, state-owned enterprises are usually regarded as the objects to be directly allocated. The information of nature of property right is visible to the outside world. It is difficult for state-owned enterprises to obtain social reputation or attention beyond non-state-owned enterprises by performing government-led social responsibility activities. This undoubtedly weakens the ability of state-owned enterprises to obtain external strategic resources through participating in targeted poverty alleviation, and furthermore, it also weakens the accounting governance effect brought about by its participation in targeted poverty alleviation.

\section{Conclusion}

Based on the perspective of accounting information quality, this article studies the impact of government poverty alleviation policies on manufacturing. The study found that compared with manufacturing companies that didn't participate, manufacturing companies that fulfil targeted poverty alleviation showed higher quality of accounting information, and there was a significant positive correlation between the two. The conclusions of the study support the hypothesis related to strategic resources, that is, the purpose of Chinese manufacturing companies' participation in targeted poverty alleviation is to obtain strategic resources support from both internal (resource integration, corporate culture) and external (social reputation, media attention). The integration of resources has increased the importance of accountancy. A responsible corporate culture will affect the producers and decision makers of accounting information, and then produce high-quality accounting information. And the improvement of social reputation and media attention increases the cost of accounting irregularities of enterprises and prompts them to provide truer and more reliable accounting information. Further research found that as a result of the natural relationship between Chinese state-owned manufacturing companies and the government, it is difficult for them to gain social reputation or attention over non-state-owned enterprises. As a result, the above-mentioned positive correlation only exists significantly in the sample of non-state-owned manufacturing companies. The enlightenment provided by this article is that, in the context of a centralized country, manufacturing companies' active participation in government-led poverty alleviation activities will help improve their accounting governance system and improve the quality of their accounting information.

\section{References}

[1] S.F. Du, H. G. Shi, Y. Q. Zhang, "Research on the Influencing Factors of the Precise Poverty Alleviation Behavior of manufacturing Companies in China_-Based on the Perspective of Social Responsibility", manufacturing Finance Research ,no. 02 ,pp. 104-115.2019.

[2] L. L. Liu, "Research on the Relationship between Enterprise Precision Poverty Alleviation and Financial Performance", Marketing Research, no. 02, pp. 30-33,2019.

[3] Z. L ,Zhang, Z. Y. Dong, "Measures in Poverty Alleviation on Corporate Performance", Journal of Shanxi University of Finance and Economics, vol. 42, no. 05, pp. 86-98,2020.

[4] Y. T. Liu, "Strictly abide by accounting standards, provide high-quality financial reports, and earnestly fulfill social responsibilities", Accounting Research, no. 01, pp. 7-13,2010.

[5] Branco, M. C., \& Lúcia Lima Rodrigues. "Corporate social responsibility and resource-based perspectives. journal of business ethics, vol. 69. no. 2, pp. 111-132,2006.

[6] F. X. Jing, B. B. Shi, X. T. Li. "Collected Essays on Finance and Economics". Accounting Research, no. 08 , pp. 24-31+96,2015. 
[7] J. Huan, Y. Li, Z. X. Duan, "Media Coverage, Ownership Property and Corporates' Precise Poverty Alleviation", East China Economic Management, vol. 34, no. 06, pp. 112-120,2020.

[8] Z. B. Yu, G. L. Tian, B. L. Qi, H. Zhang, "The Company's Governance Mechanism to which the Media Pays Attention to", Management World, no. 09, pp. 127-140,2011.

[9] J. Nie. R. Rong, Y. L. Tang, "Financial Pressure of Local Government and Targeted Poverty Alleviation Investment of Enterprises", Commercial Research, no. 03, pp. 104-112,2020.

[10] H. G. Xue, D. Wang, Q. He, "The Effect of Corporate Political Connection on Stock Price Crash Risk: An Analysis based on the intermediary Mechanism of Earnings Management", Commercial Research, no. 11, pp. 109-116,2017.

[11] L. S. Wu, "Earnings Management, Political Connections, and Corporate Tax Buedens" ,Accounting Forum, no. 01, pp. 3-16,2010.

[12] M. Huan, X. P. Xia, "An Evaluation on Specification and Power of Discretionary Accruals Models in the Chinese Context”, Nankai Business Review, vol. 12, no. 05, pp. 136 143,2009.

[13] Jones. J. J, "Earnings Management During Import Relief Investigations", Journal of Accounting Research, vol. 29, no. 2, pp. 193-228,1991. 